\title{
DESEMPENHO DE CULTIVARES DE ALFACE NA FORMAÇÃO DE MUDAS EM BANDEJAS DE ISOPOR COM DIFERENTES NÚMEROS DE CÉLULAS
}

Jhonny Kelvin Dias Martins ${ }^{1}$; Silvana Ramlow Otto Teixeira da Luz'; Paula Caroline Machado1; Bruna Firmino Enck'; Josiane Fernandes Keffer ${ }^{2}$

${ }^{1}$ Graduado (a) do curso de Agronomia, Fundação Universidade Federal de Rondônia - UNIR, (jhonny.jkdm@gmail.com) Rolim de Moura-RO, Brasil

${ }^{2}$ Mestranda em Ciências Ambientais, Universidade Federal de Mato Grosso - UFMT, Sinop- MT, Brasil.

Recebido em: 06/04/2018 - Aprovado em: 10/06/2018 - Publicado em: 20/06/2018 DOI: 10.18677/EnciBio_2018A33

\begin{abstract}
RESUMO
A alface (Lactuca sativa L.) é uma hortaliça folhosa amplamente cultivada, em grande maioria por pequenos agricultores, sendo que a produção de mudas de qualidade é essencial para um bom desenvolvimento da cultura. Diante disso, o presente trabalho teve como objetivo avaliar tipos de bandejas e diferentes cultivares na formação das mudas de alface. O experimento foi conduzido em viveiro telado no Campus experimental da Universidade Federal de Rondônia (UNIR), localizado no município de Rolim de Moura-RO. O delineamento experimental utilizado foi em blocos casualizados, em esquema fatorial $4 \times 2$, com quatro repetições, onde foram avaliadas quatro cultivares de alface sendo elas: 1- Alface americana Grandes Lagos 659 (A.G.L.659); 2- Alface Mimosa Green Salad Bowl (A.M.G. Bowl); 3Cultivar Regina (C. Regina); 4- Alface Crespa hortencia (A.C Hortencia). Submetidas a dois tipos de bandejas de poliestireno expandido (Isopor $\left.{ }^{\circledR}\right)$ de 128 células, $(25,09$ $\left.\mathrm{cm}^{3} ; 3,7 \times 5,5 \mathrm{~cm}\right)$ e 200 células $\left(12,39 \mathrm{~cm}^{3} ; 2,6 \times 5,5 \mathrm{~cm}\right)$. As variáveis analisadas foram altura da planta (ALT); número de folhas $\left(N^{\circ} \mathrm{F}\right)$; massa fresca da parte aérea (MFPA); massa fresca da raiz (MFR); comprimento da raiz (C.Raiz). Dentre as cultivares estudas a que apresentou um elevado desempenho na formação das mudas foi a cultivar Regina, já a cultivar Grandes lagos 659 obteve as menores médias. A bandeja de poliestireno de 128 células apresentou um ganho elevado nas variáveis massa fresca da raiz e comprimento da raiz, fatores importantes para um bom desenvolvimento em campo.
\end{abstract}

PALAVRAS-CHAVE: Hortaliça, Lactuca sativa L., poliestireno;

\section{PERFORMANCE OF LETTUCE CULTIVARS IN THE FORMATION OF CHANGES IN ISOPOR TRAYS WITH DIFFERENT CELL NUMBERS}

\begin{abstract}
Lettuce (Lactuca sativa L.) is a broadly cultivated leafy vegetable, mostly by small farmers, and the production of quality seedlings is essential for a good development of the crop. Therefore, the present work had as objective to evaluate the types of trays and different cultivars in the formation of lettuce seedlings. The experiment was conducted in a screened nursery at the experimental campus of the Federal University of Rondônia (UNIR), located in the municipality of Rolim de Moura-RO. The experimental design was a randomized complete block design with four
\end{abstract}


replicates, in a $4 \times 2$ factorial scheme, where four lettuce cultivars were evaluated: 1Great American Lettuce 659 (A.G.L.659); 2- Mimosa Lettuce Green Salad Bowl (A.M.G. Bowl); 3- Cultivate Regina (C. Regina); 4- Lettuce Crespa hydrangea (A.C Hortencia). They were subjected to two types of expanded polystyrene trays

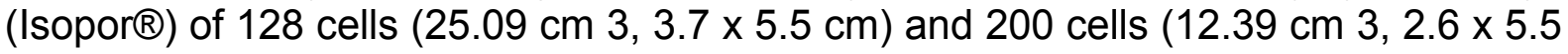
$\mathrm{cm})$. The variables analyzed were plant height (ALT); number of leaves (No. F); fresh shoot mass (MFPA); fresh root mass (MFR); length of root (C.Raiz). Among the cultivars studied, the one that presented a high performance in the formation of the seedlings was the cultivar Regina, and the Great Lakes 659 cultivar obtained the lowest averages. The 128-cell polystyrene tray presented a high gain in the variables fresh root mass and root length, important factors for good field development.

KEYWORDS: Lactuca sativa L., polystyrene, vegetable.

\section{INTRODUÇÃO}

A alface (Lactuca sativa L.) pertencente à família Asteraceae é originária de clima temperado (região do Mediterrâneo), e há séculos é cultivada no mundo inteiro para consumo em saladas e como ingrediente de sanduíches (FAVARATO et al., 2017). A alface é uma das principais espécies cultivado no Brasil, estando presente desde a produção em grande escala como na agricultura familiar. É uma hortaliça folhosa, bem aceita pelos consumidores de todo o mundo devido ao seu sabor agradável e refrescante, facilidade de preparo e, principalmente como fonte de fibras, sais minerais, sobretudo o cálcio, vitaminas, especialmente a vitamina $A$ e, apresentar baixo teor de calorias e ser de fácil digestão (MOTA et al., 2012).

O cultivo é feito de maneira intensiva e geralmente praticado pela agricultura familiar, responsável pela geração de cinco empregos diretos por hectare (ALENCAR et al., 2012). Com o aumento da população e mudança de hábito alimentar, o consumo da alface tem aumentado, tornando-se inevitável o aumento da produção (DA SILVEIRA et al., 2015). Devido ao crescente aumento no consumo dessa hortaliça, faz-se necessário o aumento na quantidade e qualidade do produto (SANTI et al., 2013). Na cadeia produtiva de hortaliças de qualidade, a formação de mudas é uma das fases mais importantes para o ciclo da cultura, influenciando diretamente no desempenho final da planta, tanto do ponto de vista nutricional como produtivo, pois existe uma relação direta entre mudas sadias e produção em campo (CARMELLO, 1995; CAMPANHARO et al., 2006).

Segundo Terra et al. (2015) com o constante aumento no desenvolvimento tecnológico e sobretudo na área da pesquisa voltada para a cadeia produtiva de hortaliças, vem surgindo novas tecnologias e métodos para o cultivo de mudas, passando de canteiros no solo para produção em recipientes, como as bandejas de poliestireno expandido.

A utilização de bandejas na produção de mudas é uma técnica que proporciona muitas vantagens ao produtor, elevando a produtividade e a qualidade do produto, além de reduzir a quantidade de semente utilizada (FILGUEIRA, 2013). Existem no mercado diversos tipos de bandejas de poliestireno expandido, apresentando variações de 128; 200; 242; 284 e 288 células, dessa forma, saber escolher de forma correta as bandejas para produção de mudas é importante (FILGUEIRA, 2013).

Outro fator de extrema importância que tem influenciado diretamente na produção das mudas é a escolha correta da cultivar a ser utilizada, pois pode proporcionar um ganho significativo na produtividade e consequentemente na qualidade do produto. Nesse contexto, Queiroz et al. (2014) relatam a importância 
da escolha de cultivares de alface, pois há uma necessidade em desenvolver genótipos tropicalizados, apesar de ser uma espécie originalmente de clima ameno, apresenta alta demanda em todas as regiões do Brasil. Recomendações de cultivares têm sido realizadas por empresas produtoras de sementes e, nem sempre esses materiais se adaptam a uma ampla faixa de ambientes (GUALBERTO et al., 2002).

Uma das principais etapas do sistema produtivo da alface é a produção de mudas de qualidade, pois delas depende o desempenho final das plantas no campo de produção, tanto do ponto de vista nutricional, quanto do tempo necessário à produção e, consequentemente, do número de ciclos produtivos possíveis por ano (FILGUEIRA, 2013). Diante disso, o objetivo desse trabalho foi avaliar o desenvolvimento de diferentes cultivares de alface submetidas a dois tipos de bandejas, 128 células e 200 células.

\section{MATERIAL E MÉTODOS}

experimento foi conduzido na casa de vegetação no Campus experimental da Universidade Federal de Rondônia (UNIR), situado no município de Rolim de Moura, Rondônia, localizado na linha 184, km 15, lado norte, sob as coordenadas geográficas Lat 1148'13"S e Long 6148'12"O a $290 \mathrm{~m}$ de altitude. O clima é tropical quente e úmido com estações de seca bem definida (junho a setembro) com chuvas intensas nos meses de novembro a março (BRASIL, 2007). A precipitação média atual é de $2.250 \mathrm{~mm}$ e a umidade relativa do ar no período chuvoso é em torno de $85 \%$. As temperaturas médias mínimas são de $24^{\circ} \mathrm{C}$ e a máximas são de $32^{\circ} \mathrm{C}$ (SEDAM, 2016).

O delineamento experimental utilizado foi em blocos casualizados, em esquema fatorial 4x2, com quatro repetições, sendo os fatores: quatro cultivares de alface: 1- Alface americana Grandes Lagos 659 (A.G.L.659), 2- Alface Mimosa Green Salad Bowl (A.M.G. Bowl), 3- Cultivar Regina (C. Regina), 4- Alface Crespa hortênsia (A.C Hortência) e dois tipos de bandejas de poliestireno expandido $\left(\right.$ Isopor $\left.^{\circledR}\right)$ : uma de 128 células $\left(25,09 \mathrm{~cm}^{3} ; 3,7 \times 5,5 \mathrm{~cm}\right)$ e outra de 200 células $(12,39$ $\left.\mathrm{cm}^{3} ; 2,6 \times 5,5 \mathrm{~cm}\right)$.

O experimento foi instalado em um viveiro telado, com sombrite $(50 \%$ de permeabilidade aos raios solares), com temperatura interna média de $28,7^{\circ} \mathrm{C}$. No decorrer do experimento foram mantidas as condições favoráveis para o pleno desenvolvimento das mudas. Utilizou-se substrato comercial Vivatto Slim Plus $e^{\circledR}$ realizou-se sua análise química (Tabela1).

TABELA 1. Análise química do substrato Vivatto Slim Plus ${ }^{\circledR}$ utilizado na produção das mudas de alface.

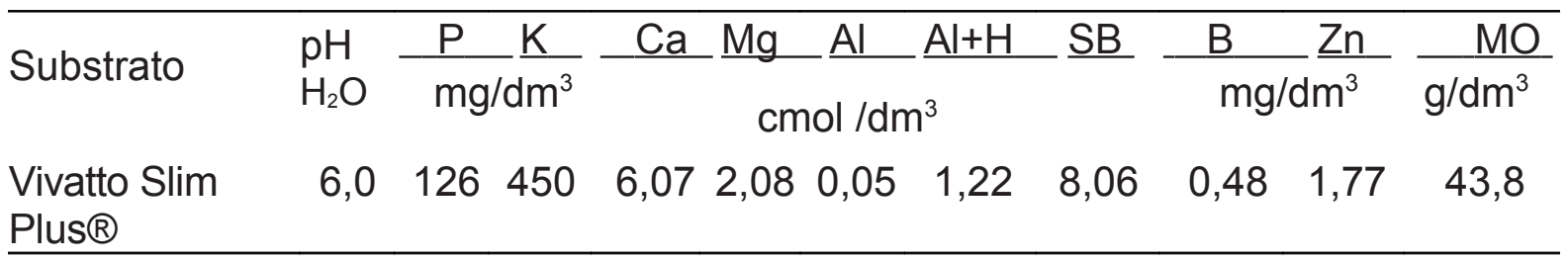

*Metodologia utilizada para a análise de P, K, Ca e Mg- Resina; Zn-DTPA; B- água quente

Antes da semeadura, molhou-se as bandejas para melhor aderência do substrato, o substrato também foi molhado antes de ser adicionado às bandejas, a 
fim de padronizar a umidade e favorecer a germinação por igual das sementes. A semeadura nas bandejas foi realizada no dia 15/01/2018, sendo colocado uma semente por célula. As avaliações ocorreram 25 dias após a semeadura. Considerou-se como unidade experimental a bandeja e, para as análises foram usadas 10 plantas por bandeja. As variáveis analisadas foram: altura de planta (ALT), obtida com o auxílio de uma régua graduada em milímetros, medindo-se da base da planta até o ápice da última folha completamente expandida; número de folhas ( $\left.\mathrm{N}^{\circ} . \mathrm{F}\right)$, contado-se somente as folhas verdadeiras completamente desenvolvidas; comprimento da raiz (C.Raiz), obtido com o auxílio de régua graduada em milímetros, medindo-se o comprimento da raiz principal.

Massa fresca da parte aérea (MFPA), obtida pela separação da parte aérea da planta de sua raiz e posterior pesagem em balança de precisão; massa fresca da raiz (MFR), por meio da lavagem das raízes em água corrente para a retirada do substrato aderido e posterior pesagem desta embalança de precisão. Os dados foram submetidos à análise de variância pelo teste $F(p \leq 0,05)$. Quando os resultados foram significativos, foi realizada a comparação de médias, utilizandose o teste de Tukey ao nível de $5 \%$ de probabilidade pelo software estatístico ASSISTAT®, versão 7.7 (SILVA; AZEVEDO 2016).

\section{RESULTADOS E DISCUSSÕES}

A análise de variância indicou efeito significativo em relação a bandeja somente, para a variável massa fresca da raiz (MFR) $(p \leq 0,05)$ e comprimento da raiz (CR) ( $p \leq 0,01)$. Para as cultivares houve efeito significativo para todas as variáveis analisadas ( $p \leq 0,01)$. Não houve interação entre os fatores bandejas e cultivares, para todas as variáveis analisadas (Tabela2).

TABELA 2. Resumo da análise de variância para Altura (ALT), Número de folhas ( $\left.N^{\circ} . F\right)$, Massa fresca da parte aérea (MFPA), Massa fresca da raiz (MFR), comprimento da raiz (C.Raiz), para as diferentes cultivares de alface em diferentes tipos de bandejas.

\begin{tabular}{|c|c|c|c|c|c|c|}
\hline \multirow{2}{*}{$\begin{array}{l}\text { Fontes de } \\
\text { Variação }\end{array}$} & \multirow[t]{2}{*}{ GL } & & \multicolumn{4}{|c|}{ QM } \\
\hline & & $\overline{A L T}$ & $N^{0} . F$ & MFPA & MFR & C. Raiz \\
\hline Bandejas (A) & 1 & $2,427^{\mathrm{ns}}$ & $2,328^{\text {ns }}$ & $1,401^{\mathrm{ns}}$ & $3,935^{*}$ & $1,523^{* *}$ \\
\hline Cultivares (B) & 3 & $15,713^{* *}$ & $8,778^{* *}$ & $13,259^{* *}$ & $14,530^{* *}$ & $5,731^{* *}$ \\
\hline Interação AxB & 3 & 1,739 ns & $0,361^{\mathrm{ns}}$ & $0,564^{\mathrm{ns}}$ & $0,466^{n s}$ & $0,785^{\mathrm{ns}}$ \\
\hline Resíduo & 24 & 0,20601 & 0,45612 & 0,01518 & 0,09837 & 1,25629 \\
\hline CV\% & - & 24,85 & 20,92 & 28,13 & 36,18 & 22,55 \\
\hline
\end{tabular}

ns= não significativo, ${ }^{* *} \mathrm{e}^{*}$ significativo ao nível de $1 \%$ e $5 \%$, respectivamente, pelo teste $\mathrm{F}$.

Ao analisar o desempenho das cultivares de alface (Lactuca sativa L.), notouse que a cultivar Regina foi a que apresentou os maiores valores médios para todas as variáveis analisadas, enquanto a cultivar Grandes Lagos 659 (A.G.L.659) apresentou os menores valores médios para todas as variáveis analisadas (Tabela 3). Observa-se que a cultivar Regina obteve um ganho na massa fresca da parte aérea (MFPA) de $0,681 \mathrm{~g}$ em relação a cultivar grandes lagos 659 . Resultados semelhantes foram encontrados por Cunha et al. (2014), ao produzirem mudas de alface utilizando a cultivar Regina submetida à substratos alternativos. Entretanto, Brzezinski et al. (2017) avaliaram o rendimento de diferentes cultivares de alface em 
União da Vitória-PR e, dentre as cultivares testadas a Grandes Lagos 659 apresentou os melhores resultados. A cultivar grandes lagos 659 é mais adaptada a condições de temperaturas amenas e, a alface é uma planta típica de inverno, capaz de suportar baixas temperaturas, inclusive a geadas leves, entretanto, sob temperaturas mais elevadas e oscilações drásticas, ocorre a redução do ciclo da cultura (YURI et al. 2002).

O menor valor médio para o número de folhas (NF) foi obtido apresentado pela cultivar grandes lagos 659. De acordo com Hernandes et al. (2001), a ação do fotoperíodo e da temperatura do ar são fatores determinantes nas mudanças dos estádios de desenvolvimento das plantas, sendo que a temperatura do ar é o principal elemento do ambiente condicionante do desenvolvimento, interferindo tanto na emissão de folhas quanto na mudança dos estádios fenológicos.

Mudas que apresentam um maior estágio inicial de desenvolvimento conseguem se desenvolver mais rapidamente em campo. Neste trabalho observouse que a cultivar Regina expressou um alto desempenho relacionado a massa fresca da raiz (MFR) $(1,452 \mathrm{~g})$ e comprimento radicular $(\mathrm{CR})(68,85 \mathrm{~mm})$. De acordo com Filgueira (2013), o sistema radicular da alface é muito ramificado e superficial, explorando apenas os primeiros $25 \mathrm{~cm}$ do solo quando as mudas são transplantadas. Franzin et al. (2005) observaram efeito da qualidade da semente na produção de mudas de alface estudando a cultivar Regina, confirmando que essa cultivar apresenta uma alta qualidade e maior índice de velocidade de emergência.

TABELA 3. Valores médios das variáveis de crescimento de diferentes cultivares de alface, Altura (ALT), Número de folhas ( $\left.N^{\circ} . F\right)$, Massa fresca da parte aérea (MFPA), Massa fresca da raiz (MFR), comprimento da raiz (C.Raiz).

\begin{tabular}{lccccc} 
CULTIVARES & ALT $(\mathrm{mm})$ & N.$F$ & MFPA $(\mathrm{g})$ & MFR $(\mathrm{g})$ & C. RAIZ $(\mathrm{mm})$ \\
\hline A.G.L.659 & $10,13 \mathrm{c}$ & $2,33 \mathrm{c}$ & $0,271 \mathrm{c}$ & $0,445 \mathrm{c}$ & $30,626 \mathrm{c}$ \\
\hline M.G.S Browl & $18,81 \mathrm{~b}$ & $3,30 \mathrm{~b}$ & $0,398 \mathrm{~b}$ & $0,756 \mathrm{~b}$ & $43,185 \mathrm{~b}$ \\
\hline C. Regina & $26,67 \mathrm{a}$ & $4,89 \mathrm{a}$ & $0,952 \mathrm{a}$ & $1,452 \mathrm{a}$ & $68,857 \mathrm{a}$ \\
\hline C.Hortencia & $10,68 \mathrm{c}$ & $3,21 \mathrm{~b}$ & $0,330 \mathrm{~b}$ & $0,813 \mathrm{~b}$ & $52,217 \mathrm{~b}$
\end{tabular}

Médias seguidas pela mesma letra não difere entre si pelo teste de Tukey, ao nível de $5 \%$ de probabilidade.

Avaliando o fator bandejas na produção das mudas de alface, verificou-se que houve efeito significativo para a massa fresca da raiz (MFR) e comprimento da raiz $(\mathrm{CR})$, variáveis importantes na produção das mudas. Observou que a bandeja de 128 células proporcionou um maior desenvolvimento com um acréscimo de $50 \%$ da massa fresca da raiz (MFR) em relação a bandeja de 200 células (Tabela 4). Recipientes com maior volume de célula proporcionaram maiores produções para mudas de alface, beterraba e pepino (LEAL et al. 2011; COSTA et al. 2012).

O valor médio do comprimento da raiz foi superior quando se utilizou a bandeja de 128 células, obtendo aumento de $17 \mathrm{~mm}$. Resultados semelhantes foram encontrados por Donegá et al. (2014) ao avaliarem recipientes na produção de mudas de tomilho, constataram que a bandeja de 128 células proporcionou maior desenvolvimento da raiz. 
TABELA 4. Valores médios de massa fresca da raiz (MFR) e comprimento da raiz (R.RAIZ) na produção de mudas da alface (Lactuca sativa L.) em diferentes bandejas.

\begin{tabular}{llc}
\hline Bandejas & MFR $(\mathrm{g})$ & C.RAIZ $(\mathrm{mm})$ \\
\hline 128 células & $0,867 \mathrm{a}$ & $62,210 \mathrm{a}$ \\
200 células & $0,578 \mathrm{~b}$ & $45,145 \mathrm{~b}$ \\
\hline $\begin{array}{l}\text { Médias seguidas pela mesma letra na coluna, não diferem entre si, } \\
\text { pelo teste Tukey ao nível de } 5 \% \text { de probabilidade. }\end{array}$
\end{tabular}

\section{CONCLUSÃO}

Dentre as cultivares analisadas, a cultivar Regina apresentou melhor desenvolvimento das mudas.

A bandeja de 128 células proporcionou melhor desempenho para a massa fresca da raiz e comprimento da raiz.

\section{REFERÊNCIAS}

AlENCAR, T. A.; TAVARES, A. T.; CHAVES, P. P. N.; FERREIRA, T. A.; NASCIMENTO, I. R. Efeito de intervalos de aplicação de urina bovina na produção de alface em cultivo protegido. Revista Verde. Mossoró, v.7, n.3, p. 53-67, 2012.

BRASIL. Ministério do Desenvolvimento Agrário. Secretaria de Desenvolvimento Territorial. Território Central - Estado de Rondônia. Plano Territorial de Desenvolvimento Rural Sustentado. [s./e.], out. 2007. Disponível em: <http://sit.mda.gov.br/download/ptdrs/ptdrs_territorio029.pdf>. Acesso em: 18 de mar. 2018.

BREZEZINSKI, C. R.; ABATI, J.; GELLER, A.; WENER, F.; ZUCARELI, C. Produção de cultivares de alface americana sob dois sistemas de cultivo. Revista Ceres, v. 64, n.1, p. 083-089, 2017. <http://dx.doi.org/10.1590/0034-737X201764010012> doi: 10.1590/0034-737X201764010012

COSTA, E.; VIEIRA, L. C. R.; LEAL, P. A. M.; JARA, M. C. S.; SILVA, P. N. L. Substrate with organosuper for cucumber seedlings formation in protected environment and polystyrene trays. Revista de Engenharia Agrícola, v.32, p.226235, 2012.

CUNHA, C. A. S.; GALLO, N. F.; GUIMARÃES, R. F. SILVA. Substratos alternativos para produção de mudas de alface e couve em sistema orgânico. Scientia Plena, v. 10, n.11, p.1-9, 2014.

DA SILVEIRA, A. L.; NETO, A. R. C.; DE SOLSA, L. N.; CHARLO, H. C. DE OLIVEIRA. Doses de fósforo para a produção de alface americana com e sem 
aplicação foliar de zinco. Revista Biotemas, v. 28, n. 1, p. 31-35, 2015. <https://doi.org/10.5007/2175-7925.2015v28n1p31> doi: 10.5007/21757925.2015v28n1p31

DONEGÁ, M. A.; FEREZINI, G.; MELLO, S. C.; MINAMI, K.; SILVA, S. R. Recipientes e substratos na produção de mudas e no cultivo hidropônico de tomilho (Thymus vulgaris L.). Revista Brasileira de Plantas Medicinais, v.16, n.2, p.271274, 2014.

GUALBERTO, R.; OlIVEIRA, P. S. R.; GUIMARÃES, A. M. Adaptabilidade e estabilidade fenotípica de diversas cultivares de alface do grupo crespa, em cultivo hidropônico.

Horticultura

Brasileira, v.27, n.1 . 2009.

<http://dx.doi.org/10.1590/S0102-05362009000100002> doi:

$10.1590 / S 0102-$

05362009000100002

LEAL, P. A. M.; COSTA, E.; SHIAVO, J. A.; PEGORARE, A. B.; Seedling formation and field production of beetroot and lettuce in Aquidauana, Mato Grosso do Sul, Brazil. Horticultura Brasileira, v. 29, p. 465-471, 2011. <http://dx.doi.org/10.1590/S0102-05362011000400004 > doi: 10.1590/S010205362011000400004

MOTA, W. F.; PEREIRA, R. D.; SANTOS, G. S.; VIEIRA, J. C. B. Agronomic and economic viability of intercropping oniom and lettuce. Horticultura Brasileira, v. 30, n. 2, p. 349-354, 2012. < http://dx.doi.org/10.1590/S0102-05362012000200028> doi: 10.1590/S0102-05362012000200028

QUEIROZ, J. P. S.; COSTA, A. J. M.; NEVES, L. G.; SEABRA JUNIOR, S.; BARELLI, M. A. A. Estabilidade fenotípica de alfaces em diferentes épocas e ambientes de cultivo. Revista Ciência Agronômica, v. 45, n. 2, p. 276-283, 2014.

SANTI A; SCARAMUZZA WLMP; NEUHAUS A; DALLACORT R; KRAUSE W; TIEPPO R. C. Desempenho agronômico de alface americana fertilizada com torta de filtro em ambiente protegido. Horticultura Brasileira, v. 31, p. 338-343, 2013. http://dx.doi.org/10.1590/S0102-05362013000200027> doi: 10.1590/S010205362013000200027

SEDAM - Secretaria de Estado do Desenvolvimento Ambiental e COGEO Coordenadoria de Geociências. Boletim climatológico de Rondônia ano 2016. Porto Velho, $\quad 2016.12, \quad$ Disponível <em: http://sedamro.wix.com/sedam_ro_focosqueimada\#!qualidade-do-ar.> Acessado em 10 janeiro. 2018.

SILVA, F. de A. S. e.; AZEVEDO, C. A. V. de. The Assistat Software Version 7.7 and its use in the analysis of experimental data. Afrrican Journal Agricultural Research, v.11, n.39, p.37333740, 2016. <http://dx.doi.org/10.5897/AJAR2016.11522> doi: 10.5897/AJAR2016.11522

TERRA, S. B.; BRAZ, G. M.; MENDES, F. B. Insumos alternativos para produção orgânica de mudas de hortaliças. Ambiência Guarapuava, v.13 n.2 p. 412 - 422 , 
2017.

10.5935/ambiencia.2017.02.10

Yuri, J. E.; Souza R. J de.; Freitas S. A. C de.; Rodrigues Júnior, J. C.; Mota, J.H. Comportamento de cultivares de alface tipo americana em Boa Esperança. Horticultura Brasileira, v. 20, p.229-232, 2002. <http://dx.doi.org/10.1590/S010205362002000200023> doi: 10.1590/S0102-05362002000200023 